\title{
Prevalence, Awareness, and Treatment of Hepatitis C Virus Infection in South Korea: Evidence from the Korea National Health and Nutrition Examination Survey
}

\author{
Kyung-Ah Kim and June Sung Lee \\ Department of Internal Medicine, Inje University Ilsan Paik Hospital, Goyang, Korea
}

Background/Aims: This study aimed to investigate the epidemiology of hepatitis $\mathrm{C}$ virus (HCV) infection in the Korean general population and the awareness and treatment status of HCV infection among anti-HCV-positive persons. Methods: We used data from the Korea National Health and Nutrition Examination Survey (KNHNES) collected between 2012 and 2016. All the participants aged $\geq 10$ years in the KNHNES were tested for the anti-HCV antibody. Anti-HCV-positive persons were tested for HCV RNA and assessed for their awareness and treatment experience regarding HCV infection. Results: The prevalence of anti-HCV was 0.66\% (95\% confidence interval, $0.56 \%$ to $0.78 \%$ ) among Koreans aged $\geq 10$ years, representing an estimated 278,819 anti-HCV-positive persons, and $0.71 \%$ (95\% confidence interval, $0.60 \%$ to $0.84 \%$ ) among Koreans aged $\geq 20$ years. The prevalence of anti-HCV increased with age and had significant geographic variation. The positive rate of HCV RNA in anti-HCV-positive persons was $33.5 \%$ and increased with age. The rate of HCV infection awareness was 15.2\% (35/250) among antiHCV-positive persons and 30.5\% (18/59) among HCV RNApositive persons. Among the participants, 13.5\% of HCV RNA-positive persons had been treated for HCV infection. Conclusions: The prevalence of anti-HCV among Koreans aged $\geq 20$ years was $0.71 \%$; one-third of anti-HCV-positive persons tested HCV RNA-positive. The awareness and treatment rates of HCV infection were low among HCV-infected persons. Therefore, active measures should be taken to diagnose and treat persons unaware of HCV infection. (Gut Liver 2020;14:644-651)

Key Words: Hepatitis C; Prevalence; Awareness; Therapeutics; Population surveillance

\section{INTRODUCTION}

Hepatitis C virus (HCV) infection is a major cause of liver cirrhosis and hepatocellular carcinoma (HCC) and affects at least 71 million people worldwide. ${ }^{1}$ It insidiously progresses to liver cirrhosis over 20 to 30 years and leads to a $1 \%$ to $7 \%$ annual risk of HCC and a 3\% to 6\% annual risk of hepatic decompensation. $^{2}$

Considering that the current HCV therapies, direct-acting antiviral agents (DAAs), have shown a remarkably high cure rate of over 90\%, ${ }^{3,4}$ early diagnosis and treatment before the onset of advanced liver fibrosis or cirrhosis are key to reducing the HCV-related morbidity and mortality rate. However, most HCVinfected patients are asymptomatic, and they are diagnosed at advanced symptomatic stages including decompensated cirrhosis or HCC. Only about 20\% of HCV-infected persons are aware of their infection status, and only 7\% of patients diagnosed with chronic hepatitis $\mathrm{C}$ have initiated antiviral therapy. ${ }^{1}$ In response to the "HCV cascade of care," the World Health Organization has advocated for an HCV elimination strategy aimed at achieving a $65 \%$ reduction in the HCV-associated mortality rate and an $80 \%$ reduction in HCV incidence by diagnosing 90\% of $\mathrm{HCV}$-infected persons and treating $80 \%$ of eligible people by $2030 .^{5}$ The strategy emphasized comprehension of the national and subnational epidemiology to screen hidden HCV infections. The epidemiology of HCV infection varies among and within countries.

The anti-HCV prevalence in Korea has been reported to range from $0.41 \%$ to $2.1 \%$ among studies, most of which were limited by the representativeness of their study populations. ${ }^{6,7}$ The only nationwide study conducted in 2009 reported an HCV seroprevalence of $0.76 \%$. Moreover, there are no nationwide studies on the awareness and treatment rate of HCV infection in the

Correspondence to: Kyung-Ah Kim

Department of Internal Medicine, Inje University Ilsan Paik Hospital, 170 Juhwa-ro, Ilsanseo-gu, Goyang 10380, Korea

Tel: +81-31-910-7847, Fax: +82-31-910-7219, E-mail: kakim@paik.ac.kr

Received on August 2, 2019. Revised on October 11, 2019. Accepted on October 12, 2019. Published online December 18, 2019. pISSN 1976-2283 eISSN 2005-1212 https://doi.org/10.5009/gnl19272

(c) This is an Open Access article distributed under the terms of the Creative Commons Attribution Non-Commercial License (http://creativecommons.org/licenses/by-nc/4.0) which permits unrestricted non-commercial use, distribution, and reproduction in any medium, provided the original work is properly cited. 
Korean general population.

In light of the clinical significance of HCV infection, the Korean government introduced tests and questionnaire surveys for HCV infection into the Korea National Health and Nutrition Examination Survey (KNHNES) in 2012 for the first time.

This study aimed to investigate the nationwide populationbased prevalence of anti-HCV and HCV RNA, and the aware-

Table 1. Study Population

\begin{tabular}{lcc}
\hline & Total & $\begin{array}{c}\text { Anti-HCV-positive } \\
\text { persons }\end{array}$ \\
\hline Unweighted count & 29,920 & 246 \\
Weighted count & $42,187,199$ & 278,819 \\
Age, mean \pm SE, yr & $42.7 \pm 0.18$ & $55.1 \pm 1.4$ \\
Male to female ratio & 1.03 & 0.93 \\
\hline
\end{tabular}

HCV, hepatitis C virus; SE, standard error. ness and treatment status of HCV infection by analyzing the KNHNES data from 2012 to 2016.

\section{MTERIALS AND METHODS}

\section{Data source and study population}

This study used data from the KNHNES from 2012 to 2016. The KNHNES is a national surveillance system that has been assessing the health and nutritional status of Koreans since 1998. This nationally representative cross-sectional survey assesses approximately 10,000 individuals each year as a survey sample and collects information on socioeconomic status, health-related behaviors, quality of life, health utilization, anthropometric measures, biochemical and clinical profiles for non-communicable diseases, and dietary intake via a health interview. ${ }^{8}$ The survey involves a complex, stratified, multistage probability sample of the non-institutionalized Korean civilian population.

Table 2. Prevalence of Anti-HCV by Demographics and Potential Risk Factors

\begin{tabular}{|c|c|c|c|}
\hline Variable & $\begin{array}{l}\text { Prevalence of anti-HCV (\%) } \\
\qquad(95 \% \mathrm{CI})\end{array}$ & $\begin{array}{l}\text { Unadjusted OR } \\
\quad(95 \% \mathrm{CI})\end{array}$ & $\begin{array}{l}\text { Adjusted OR } \\
(95 \% \mathrm{CI})^{*}\end{array}$ \\
\hline Total (age $\geq 10$ yr) & $0.66(0.56-0.78)$ & & \\
\hline Age $\geq 20$ yr & $0.71(0.60-0.84)$ & & \\
\hline \multicolumn{4}{|l|}{ Sex } \\
\hline Male & $0.63(0.50-0.79)$ & Reference & Reference \\
\hline Female & $0.69(0.56-0.86)$ & $1.10(0.82-1.49)$ & $0.99(0.73-1.36)$ \\
\hline \multicolumn{4}{|l|}{ Age, yr } \\
\hline $10-19$ & $0.32(0.15-0.67)$ & $1.81(0.58-5.63)$ & \\
\hline $20-29$ & $0.17(0.08-0.40)$ & Reference & Reference \\
\hline $30-39$ & $0.23(0.13-0.41)$ & $1.34(0.48-3.69)$ & $0.99(0.34-2.86)$ \\
\hline $40-49$ & $0.60(0.39-0.92)$ & $3.44(1.33-14.10)$ & $2.92(1.10-7.72)$ \\
\hline $50-59$ & $0.98(0.69-1.40)$ & $5.63(2.35-14.10)$ & $4.16(1.58-10.94)$ \\
\hline $60-69$ & $1.07(0.80-1.44)$ & $6.18(2.53-15.10)$ & $3.82(1.42-10.03)$ \\
\hline$\geq 70$ & $1.93(1.47-2.53)$ & $9.71(3.91-24.12)$ & $6.29(2.35-15.83)$ \\
\hline \multicolumn{4}{|l|}{ Area of residence } \\
\hline Urban & $0.57(0.47-0.68)$ & Reference & Reference \\
\hline Rural & $1.11(0.76-1.61)$ & 1.96 (1.29-2.99) & $1.37(0.89-2.10)$ \\
\hline \multicolumn{4}{|l|}{ Family income } \\
\hline Low to mid-low & $0.93(0.75-1.16)$ & $1.91(1.39-2.61)$ & $1.09(0.73-2.73)$ \\
\hline Mid-high to high & $0.49(0.39-0.62)$ & Reference & Reference \\
\hline \multicolumn{4}{|l|}{ Education $^{\dagger}$} \\
\hline$<$ High school & $1.10(0.89-1.35)$ & $2.52(1.85-3.44)$ & $1.82(1.22-2.73)$ \\
\hline$\geq$ High school & $0.44(0.34-0.56)$ & Reference & Reference \\
\hline \multicolumn{4}{|l|}{ ALT level, U/L } \\
\hline$<40$ & $0.60(0.51-0.71)$ & Reference & Reference \\
\hline$\geq 40$ & $1.29(0.86-1.95)$ & $2.00(1.25-3.18)$ & $2.69(1.72-4.20)$ \\
\hline
\end{tabular}

$\mathrm{HCV}$, hepatitis C virus; CI, confidence interval; OR, odds ratio; ALT, alanine aminotransferase.

*Adjusted for age, sex, area of residence, family income, education and serum ALT level in persons aged $\geq 20$ years; ${ }^{\dagger}$ Education level was compared in persons aged $\geq 20$ years. 
The KNHNES introduced anti-HCV antibody tests for individuals aged $\geq 10$ years from 2012 to 2016 and serum HCV RNA tests for anti-HCV-positive persons from 2012 to 2015. Anti-HCV antibody tests were performed using chemiluminescent microparticle immunoassay (Architect anti-HCV, Abbott Diagnostics, Germany) and HCV RNA was assayed via real-time polymerase chain reaction (Cobas AmpliPrep/Cobas TaqMan System, Roche, Germany). Survey questionnaires regarding the awareness and treatment of HCV infection were also administered to anti-HCV-positive persons.

Written informed consent was provided by all participants of the KNHNES. The protocols for KNHNES were approved by the institutional review board of the Korea Centers for Disease Control and Prevention. The study protocol was approved by the Institutional Review Board of Inje University Ilsan Paik Hospital, Republic of Korea (IRB number: 2019-06-017).

\section{Data analyses}

The anti-HCV antibody prevalence was assessed according to age, sex, area of residence, education level, family income, and serum level of alanine aminotransferase (ALT). The proportions of HCV RNA positivity and its associated factors were assessed among anti-HCV-positive individuals.

The awareness rate was defined as the ratio of the number of individuals who had been diagnosed with hepatitis $\mathrm{C}$ by a doctor to the number of anti-HCV-positive or HCV RNA-positive individuals. The treatment rate was defined as the ratio of the number of individuals who had been treated for hepatitis $\mathrm{C}$ to the number of anti-HCV-positive or HCV RNA-positive individuals.

\section{Statistical analyses}

To obtain representative estimates of the non-institutionalized Korean civilian population, the anti-HCV prevalence was assessed by applying survey sample weights which were constructed for sample participants to represent the Korean population by accounting for the complex survey design, survey non-response and post-stratification. The weights based on the inverse of selection probabilities and inverse of response rates were modified by adjusting them to the sex- and age-specific Korean populations. ${ }^{8}$

Univariable logistic regression analyses were performed to compare the prevalence of anti-HCV among demographic and socioeconomic factors. Multivariable logistic regression was used to estimate the odds ratios of anti-HCV seroprevalence while controlling for covariates. Continuous variables were assessed using the t-test and categorical variables were compared using the chi-square test. Statistical analyses were performed using SPSS version 25 (SPSS Inc., Chicago, IL, USA). All pvalues were two-sided, and $\mathrm{p}<0.05$ was considered statistically significant.

\section{RESULTS}

\section{Anti-HCV prevalence}

A total of 29,920 people were recruited for the survey from

Table 3. Prevalence of Anti-HCV According to Regions

\begin{tabular}{lccc}
\hline \multicolumn{1}{c}{ Region } & $\begin{array}{c}\text { Prevalence of anti-HCV } \\
(95 \% \mathrm{CI})\end{array}$ & $\begin{array}{c}\text { Unadjusted OR } \\
(95 \% \mathrm{CI})\end{array}$ & $\begin{array}{c}\text { Adjusted for age OR } \\
(95 \% \mathrm{CI})\end{array}$ \\
\hline Seoul & $0.49(0.34-0.72)$ & Reference & Reference \\
Busan & $1.06(0.69-1.63)$ & $2.16(1.21-3.86)$ & $2.23(1.12-3.66)$ \\
Daegu & $0.44(0.20-0.98)$ & $0.89(0.36-2.18)$ & $0.87(0.35-2.13)$ \\
Incheon & $0.23(0.09-0.56)$ & $0.46(0.17-1.23)$ & $0.47(0.18-1.25)$ \\
Gwangju & $0.98(0.34-2.78)$ & $2.00(0.65-6.18)$ & $2.03(0.67-6.18)$ \\
Daejeon & $0.62(0.33-1.16)$ & $1.26(0.60-2.34)$ & $1.36(0.65-2.85)$ \\
Ulsan & $1.10(0.54-2.24)$ & $2.24(0.99-5.08)$ & $2.47(1.10-5.52)$ \\
Gyeonggi & $0.50(0.37-0.68)$ & $1.01(0.62-1.66)$ & $1.05(0.64-1.73)$ \\
Gangwon & $0.45(0.19-1.07)$ & $0.91(0.35-2.37)$ & $0.83(0.32-2.17)$ \\
Chungbuk & $1.09(0.62-1.92)$ & $2.22(1.11-4.43)$ & $1.93(0.94-3.96)$ \\
Chungnam & $0.74(0.37-1.44)$ & $1.49(0.68-3.25)$ & $1.39(0.64-3.05)$ \\
Jeonbuk & $0.74(0.35-1.54)$ & $1.50(0.65-3.47)$ & $1.28(0.56-2.91)$ \\
Jeonnam & $0.44(0.19-1.02)$ & $0.89(0.35-2.25)$ & $0.75(0.29-1.95)$ \\
Gyeongbuk & $0.85(0.41-1.78)$ & $1.74(0.75-4.01)$ & $1.48(0.64-3.39)$ \\
Gyeongnam & $1.46(0.74-2.87)$ & $2.99(1.36-6.57)$ & $2.87(1.30-6.34)$ \\
Jeju & $0.39(0.12-1.25)$ & $0.78(0.23-2.70)$ & $0.76(0.22-2.64)$ \\
\hline
\end{tabular}

HCV, hepatitis C virus; CI, confidence interval; OR, odds ratio. 
2012 to 2016 (6,308 in 2012, 5,938 in 2013, 5,518 in 2014, 5,856 in 2015, and 6,546 in 2016). Anti-HCV was positive in 246 persons among 29,920 population. The weighted count of the study population was $42,187,199$ (mean age, 42.5; male to female ratio, 1.03). The weighted count of anti-HCV-positive persons was 278,819 (mean age, 55.1; male to female ratio, 0.93) (Table 1). The weighted anti-HCV prevalence among Koreans aged $\geq 10$ years was $0.66 \%$ (95\% confidence interval [CI], 0.56\% to $0.78 \%$ ) and $0.71 \%$ among Koreans aged $\geq 20$ years $(95 \%$ CI, $0.60 \%$ to $0.84 \%$ ). The anti-HCV prevalence did not differ between males and females.

The age-specific anti-HCV prevalence was 0.32\% (95\% CI, $0.15 \%$ to $0.67 \%$ ) among individuals aged 10 to 19 years, $0.17 \%$ (95\% CI, $0.08 \%$ to $0.40 \%$ ) among those aged 20 to 29 years, $0.23 \%$ (95\% CI, 0.13\% to $0.41 \%$ ) among those aged 30 to 39 years, $0.60 \%$ (95\% CI, 0.39\% to 0.92\%) among those aged 40 to 49 years, $0.98 \%$ (95\% CI, 0.69\% to $1.40 \%$ ) among those aged 50 to 59 years, $1.07 \%$ (95\% CI, $0.80 \%$ to $1.44 \%$ ) among those aged 60 to 69 years, and $1.93 \%$ (95\% CI, $1.47 \%$ to $2.53 \%$ ) among those aged 70 years or older. Both the unadjusted and adjusted age-specific anti-HCV prevalence rates increased with age (Table 2).

There were significant differences in HCV seroprevalence among the various regions. The crude anti-HCV prevalence was significantly higher in Chungbuk, Busan, and Gyeongnam compared with Seoul. It was significantly higher in the southeastern area of Korea encompassing Busan (1.06\%), Gyeongnam (1.46\%), and Ulsan (1.10\%) compared with Seoul (0.49\%) after adjusting for age (Table 3).

\section{Risk factors for anti-HCV positivity}

In the univariable analysis, the HCV seroprevalence was significantly higher in the settings of old age, rural areas, low family income, and education level below high school. However, only old age and education level below high school were significantly associated with a high prevalence of HCV infection in the multivariable analysis (Table 2).

The anti-HCV prevalence was also significantly higher in persons with serum ALT levels $\geq 40 \mathrm{U} / \mathrm{L}$ compared with those with ALT levels < 40 U/L (1.29\% vs 0.60\%; odds ratio, 2.69).

\section{Prevalence of HCV RNA positivity}

The HCV RNA was assayed in 187 out of 188 anti-HCVpositive persons from 2012 to 2015. The serum HCV RNA was detected in 33.5\% of anti-HCV-positive persons (63/188) (Table 4). The weighted count of HCV RNA-positive persons was estimated to be 81,596 . Eight HCV RNA-positive and three HCV RNA-negative persons had been treated for hepatitis C. The HCV RNA positivity rate increased with age $(p=0.024)$ but was not different between males and females (Table 4). In multivariable logistic analysis, only age is a risk factor for HCV RNA positivity (Supplementary Table 1). Elevated serum ALT levels were significantly more frequent in HCV RNA-positive persons compared with HCV RNA-negative persons (33.3\% vs 9.7\%, $\mathrm{p}<0.001$ ). The anti-HCV signal-to-cutoff (S/CO) ratio was significantly higher in HCV RNA-positive persons compared with HCV RNA-negative persons $(13.99 \pm 2.26$ vs $3.43 \pm 3.44$, $\mathrm{p}<0.001)$.

\section{Awareness and treatment rate of HCV infection}

The response rates to the questionnaires regarding the awareness and treatment experience of hepatitis C were both 93.5\% (230/246). Among anti-HCV-positive persons, 15.2\% (35/230) had been diagnosed with hepatitis $\mathrm{C}$ by a doctor and $5.2 \%$ $(12 / 230)$ had been treated for hepatitis C. Two persons were diagnosed with liver cancer $(0.8 \%)$ and five were diagnosed with liver cirrhosis $(2.1 \%)$. The awareness and treatment rates were 30.5\% (18/59) and 13.5\% (8/59) among HCV RNA-positive persons from 2012 to 2015 (Table 5).

There were no differences in the awareness rate of HCV infection according to age, sex, economic status, education level, and

Table 4. Characteristics of HCV RNA-Positive Persons

\begin{tabular}{|c|c|c|c|}
\hline \multirow{2}{*}{ Characteristic } & \multicolumn{2}{|c|}{ Anti-HCV-positive persons $(\mathrm{n}=188)^{*}$} & \multirow{2}{*}{ p-value } \\
\hline & HCV RNA-positive & HCV RNA-negative & \\
\hline Total & $33.5(63)$ & $66.0(124)$ & \\
\hline Age, yr & $64.7 \pm 13.1$ & $57.3 \pm 16.7$ & 0.003 \\
\hline Sex & & & 0.640 \\
\hline Male $(n=76)$ & $31.6(24)$ & $68.4(52)$ & \\
\hline Female $(n=111)$ & $34.8(39)$ & $64.3(72)$ & \\
\hline S/CO of HCV antibody & $13.99 \pm 2.26$ & $3.43 \pm 3.44$ & $<0.001$ \\
\hline $\mathrm{ALT} \geq 40 \mathrm{U} / \mathrm{L}$ & $33.3(21 / 63)$ & $9.7(12 / 124)$ & $<0.001$ \\
\hline ALT $\geq 34 \mathrm{U} / \mathrm{L}$ for men $\& \geq 30 \mathrm{U} / \mathrm{L}$ for women & $41.3(26 / 63)$ & $12.9(16 / 124)$ & $<0.001$ \\
\hline
\end{tabular}

Data are presented as percent (number) or mean \pm SD.

$\mathrm{HCV}$, hepatitis $\mathrm{C}$ virus; $\mathrm{S} / \mathrm{CO}$, sign-to-cutoff ratio; ALT, alanine aminotransferase.

*HCV RNA was measured between 2012 and 2015. 
Table 5. Awareness and Treatment of HCV Infection

\begin{tabular}{|c|c|c|c|c|}
\hline \multirow{2}{*}{ Variable } & \multicolumn{2}{|c|}{ Anti-HCV-positive persons } & \multicolumn{2}{|c|}{ HCV RNA-positive persons* } \\
\hline & Yes & $\mathrm{p}$-value & Yes & $\mathrm{p}$-value \\
\hline \multicolumn{5}{|c|}{ Diagnosed as hepatitis C by a doctor } \\
\hline All responders & $15.2(35 / 230)$ & & $30.5(18 / 59)$ & \\
\hline Age group, yr & & 0.310 & & 0.768 \\
\hline$<40$ & $3.8(1 / 26)$ & & $0.0(0 / 2)$ & \\
\hline $40-49$ & $24.0(6 / 25)$ & & $50.0(2 / 4)$ & \\
\hline $50-59$ & $13.0(7 / 54)$ & & $25.0(3 / 11)$ & \\
\hline $60-69$ & $18.5(10 / 54)$ & & $33.3(5 / 15)$ & \\
\hline$\geq 70$ & $15.5(11 / 71)$ & & $30.8(8 / 26)$ & \\
\hline Sex & & 0.179 & & 0.084 \\
\hline Male & $18.8(19 / 101)$ & & $43.5(10 / 23)$ & \\
\hline Female & $12.4(16 / 129)$ & & $22.2(8 / 36)$ & \\
\hline Area of residence & & 0.651 & & 0.755 \\
\hline Rural & $16.9(11 / 65)$ & & $33.3(6 / 18)$ & \\
\hline Urban & $14.5(24 / 165)$ & & $29.3(12 / 41)$ & \\
\hline Education & & 0.102 & & 0.005 \\
\hline$<$ High school & $12.2(17 / 139)$ & & $18.9(7 / 37)$ & \\
\hline$\geq$ High school & $20.2(18 / 89)$ & & $55.5(11 / 20)$ & \\
\hline Family income & & 0.209 & & 0.575 \\
\hline Low to mid-low & $17.8(24 / 135)$ & & $32.6(14 / 43)$ & \\
\hline Mid-high to high & $11.7(11 / 94)$ & & $25.0(4 / 16)$ & \\
\hline Prevalence of anti-HCV & & 0.289 & & 0.354 \\
\hline Lower prevalent area & $13.8(24 / 174)$ & & $26.8(11 / 41)$ & \\
\hline Higher prevalent area & $19.6(11 / 56)$ & & $38.9(7 / 18)$ & \\
\hline ALT, U/L & & 0.082 & & 0.592 \\
\hline$<40$ & $13.4(26 / 194)$ & & $28.2(11 / 39)$ & \\
\hline$\geq 40$ & $25.0(9 / 36)$ & & $35.0(7 / 20)$ & \\
\hline Treatment for HCV infection & $5.2(12 / 230)$ & & $13.5(8 / 59)$ & \\
\hline
\end{tabular}

Data are presented as percent (number/number).

HCV, hepatitis C virus; ALT, alanine aminotransferase.

*HCV RNA was measured between 2012 and 2015.

area of residence among anti-HCV-positive persons. However, a higher education level was associated with a higher awareness among HCV RNA-positive persons. The awareness rate of hepatitis C was significantly higher in HCV RNA-positive persons compared with HCV RNA negative persons (30.5\% vs $8.8 \%$, $\mathrm{p}<0.001)$ and tended to be higher in persons with ALT level $\geq 40$ U/L compared to those with serum ALT level $<40 \mathrm{U} / \mathrm{L}$ (25.0\% vs 13.4\%, $\mathrm{p}=0.082$ ) (Table 5).

\section{DISCUSSION}

This study investigated the population-based prevalence of anti-HCV and HCV RNA using nationwide representative data. The anti-HCV prevalence for Korea has been reported to range from $0.41 \%$ to $2.1 \%$ among studies, most of which were limited by the representativeness of their study populations. ${ }^{6,7} \mathrm{~A}$ mos recent nationwide study on HCV seroprevalence using data of around 30,000 health check-up examinees in 2009 reported an anti-HCV prevalence of $0.78 \%$ among Koreans older than 20 years. ${ }^{7}$ The anti-HCV prevalence from 2012 to 2016 in this study was $0.71 \%$ among Koreans aged $\geq 20$ years and $0.66 \%$ among those aged $\geq 10$ years, which is similar to the results of a previous study conducted in 2009.

The anti-HCV prevalence increased with age and showed a seroprevalence of $0.17 \%$ among persons aged 20 to 29 years and 1.93\% among those aged 70 years or older, which was also consistent with the results of previous studies. ${ }^{6,7}$ In the univariable analysis, residence in a rural area and low family income were significantly associated with a higher HCV seroprevalence although these associations were attenuated in the multivariable 
analysis, suggesting that these factors were associated with old age. An education level below high school was significantly associated with HCV seroprevalence even after adjusting for age.

There was also a consistent geographic variation in the prevalence of anti-HCV reported in the previous study. ${ }^{7}$ The reason for this geographic variation in Korea is unclear, but it was reported that risky behaviors were more frequent in prevalent areas. $^{9}$

As expected, the HCV seroprevalence was higher among persons with ALT level $\geq 40 \mathrm{U} / \mathrm{L}$ compared with those with ALT level $<40 \mathrm{U} / \mathrm{L}$ (1.29\% vs 0.60\%). It was reported that about 30\% to $40 \%$ of patients with chronic hepatitis $\mathrm{C}$ had persistently normal ALT levels. ${ }^{10,11}$ In this study, $82.4 \%$ of anti-HCV positive and $66.7 \%$ of HCV RNA-positive persons had serum ALT levels $<40$ $\mathrm{U} / \mathrm{L}$, which seemed higher compared with the reports of previous studies although ALT was measured only one time in this study. When stricter cutoff levels are applied (34 U/L for men and 30 U/L for women), less than half of HCV RNA-positive persons had elevated ALT levels. This finding confirms the limitation of liver biochemistry alone in detecting HCV infection.

There are few studies on the prevalence of HCV RNA positivity in the Korean general population. A study using the data of blood donors reported that only 5.3\% of anti-HCV-positive persons had detectable serum HCV RNA levels, ${ }^{12}$ whereas a study of health check-up examinees reported an HCV RNA-positivity rate of 56.1\% among anti-HCV-positive persons. ${ }^{7}$ The serum HCV RNA positivity rate among anti-HCV-positive persons was $33.5 \%$ in this study, which is much lower than that of other countries. ${ }^{13,14}$ Considering that only 2.4\% (3/124) of anti-HCVpositive and HCV RNA-negative persons had been treated for hepatitis C, anti-HCV positivity and HCV RNA negativity can be interpreted to imply spontaneous clearance of HCV infection, false positivity, or transient undetectable viremia which can be observed in acute infection but rarely occur in chronic infection. ${ }^{15}$ In the United States National Health and Nutrition Examination Study (NHANES), the false positivity rate among positive anti-HCV test results was $22 \%$ and indeterminate in $10 \%$ overall via a recombinant immunoblot and the false negativity rate was $63 \%$ in the setting of S/CO ratio $\leq 8.0 .{ }^{16}$ In this study, the anti-HCV S/CO ratio was 8.0 or below in $61 \%$ (156/246) and significantly higher in HCV RNA-positive persons $(13.99 \pm 2.26$ vs $3.43 \pm 3.44, p<0.001)$. The spontaneous clearance rate of HCV infection was reported to be $36.1 \%$ in a recent metanalysis. ${ }^{17}$ Younger age, genotype 1 infection, hepatitis B virus (HBV) co-infection, and IL28B polymorphism were associated with spontaneous clearance of HCV infection. ${ }^{18}$ Endemic $\mathrm{HBV}$ infection, ${ }^{19}$ predominant genotype $1 \mathrm{HCV},{ }^{6}$ and the predominant C/C type of IL28B in Korea ${ }^{20}$ might result in a higher rate of spontaneous HCV infection clearance. The spontaneous clearance rate of acute hepatitis $\mathrm{C}$ in Korea was reported to be 44.7\%. ${ }^{21}$ The prevalence of HCV RNA-positivity increased with age, which may suggest a higher spontaneous clearance rate among younger persons.

The awareness rate of HCV infection is estimated to be $20 \%$ worldwide $^{1}$ and varies among countries and regions according to socioeconomic status and health policy. ${ }^{22}$ The awareness rate of HCV infection among anti-HCV-positive Koreans was reported to be $28 \%$ to $34 \%,{ }^{23,24}$ which was much higher than the value of 15.2\% obtained in this study. These differences in awareness among studies might result from the differences in study populations among the HCC epidemiology survey, cancer screening program, and the KNHNES. There has been no study on the awareness among HCV RNA-positive Koreans. The awareness rate of HCV infection among HCV RNA-positive persons was 30\% in this study. It was not significantly different according to age, sex, area of residence, family income, and ALT levels, whereas higher education level was associated with a higher awareness rate. The awareness rate of HCV infection in Korea (30\%) is much lower than in the United States or some European countries. ${ }^{22,25,26}$ There are currently no screening programs for HCV infection in Korea. Therefore, efforts are needed to raise the awareness rate of HCV infection.

A study using the Korean national health insurance claims data estimated that $13.9 \%$ of patients with chronic HCV infection had been treated with interferon or peginterferon \pm ribavirin. ${ }^{27}$ This study showed that $13.5 \%$ of persons with chronic HCV infection had been treated. Because DAAs have been used in Korea since 2015, treatment regimens for HCV infection in this study were based on interferon or peginterferon. The treatment rate might have increased further since the introduction of DAAs, and it is necessary to keep track of it.

The limitation of this study is the relatively small number of HCV RNA-positive subjects, which hinders a more detailed analysis of the factors associated with hepatitis C viremia. In addition, we did not have any detailed information on HCV genotypes, treatment regimens, or risk behaviors for HCV infection. However, the strength of this study was that it investigated the prevalence of HCV and HCV RNA positivity in representative samples of the Korean general population. Moreover, we believe that this is the first report on the awareness and treatment status of HCV RNA-positive Koreans.

In conclusion, the anti-HCV prevalence among adult Koreans was $0.71 \%$ with no gender difference and increased with age About one-third of anti-HCV-positive Koreans had positive serum HCV RNA test results. The awareness and treatment of HCV infection among HCV RNA-positive persons were as low as 30.5\% and $13.5 \%$, respectively. Therefore, active measures aimed at raising the awareness and treatment rate among HCV-infected persons should be taken to move towards HCV elimination in the era of DAAs.

\section{CONFLICTS OF INTEREST}

No potential conflict of interest relevant to this article was reported. 


\section{ACKNOWLEDGEMENTS}

This study was supported by the 2018 Inje University Research Grant.

\section{AUTHOR CONTRIBUTIONS}

Study concept and design: K.A.K., J.S.L. Data acquisition: K.A.K. Data analysis and interpretation: K.A.K. Drafting of the manuscript: K.A.K. Critical revision of the manuscript for important intellectual content: K.A.K., J.S.L. Statistical analysis: K.A.K. All authors reviewed and approved the final manuscript.

\section{ORCID}

$\begin{array}{ll}\text { Kyung-Ah Kim } & \text { https://orcid.org/0000-0002-6128-6407 } \\ \text { June Sung Lee } & \text { https://orcid.org/0000-0002-1803-9398 }\end{array}$

\section{REFERENCES}

1. World Health Organization (WHO). Global hepatitis report, 2017 [Internet]. Geneva: WHO; c2017 [cited 2019 Oct 23]. Available from: http://apps.who.int/iris/bitstream/10665/255016/1/9789241565455eng.pdf?ua=1.

2. Westbrook RH, Dusheiko G. Natural history of hepatitis C. J Hepatol 2014;61(1 Suppl):S58-S68.

3. European Association for the Study of the Liver. EASL recommendations on treatment of hepatitis C 2016. J Hepatol 2017;66:153194.

4. AASLD-IDSA HCV Guidance Panel. Hepatitis C Guidance 2018 Update: AASLD-IDSA recommendations for testing, managing, and treating hepatitis C virus infection. Clin Infect Dis 2018;67:1477-1492.

5. World Health Organization (WHO). Combating hepatitis B and C to reach elimination by 2030 [Internet]. Geneva: WHO; c2016 [cited 2019 Oct 23]. Available from: http://apps.who.int/iris/bitstream/10665/206453/1/WHO_HIV_2016.04_eng.pdf?ua=1.

6. Shin HR. Epidemiology of hepatitis $C$ virus in Korea. Intervirology 2006;49:18-22.

7. Kim DY, Kim IH, Jeong SH, et al. A nationwide seroepidemiology of hepatitis C virus infection in South Korea. Liver Int 2013;33:586-594.

8. Kweon S, Kim Y, Jang MJ, et al. Data resource profile: the Korea National Health and Nutrition Examination Survey (KNHANES). Int J Epidemiol 2014;43:69-77.

9. Kim KA, Jeong SH, Jang ES, et al. Geographic differences in the epidemiological features of HCV infection in Korea. Clin Mol Hepatol 2014;20:361-367.

10. Marcellin P, Lévy S, Erlinger S. Therapy of hepatitis C: patients with normal aminotransferase levels. Hepatology 1997;26(3 Suppl 1):133S-136S.
11. Puoti C, Castellacci R, Montagnese F, et al. Histological and virological features and follow-up of hepatitis $\mathrm{C}$ virus carriers with normal aminotransferase levels: the Italian prospective study of the asymptomatic C carriers (ISACC). J Hepatol 2002;37:117-123.

12. Oh DJ, Park YM, Seo YI, Lee JS, Lee JY. Prevalence of hepatitis $\mathrm{C}$ virus infections and distribution of hepatitis $\mathrm{C}$ virus genotypes among Korean blood donors. Ann Lab Med 2012;32:210-215.

13. Hofmeister MG, Rosenthal EM, Barker LK, et al. Estimating Prevalence of Hepatitis C Virus Infection in the United States, 20132016. Hepatology 2019;69:1020-1031.

14. Petruzziello A, Marigliano S, Loquercio G, Cozzolino A, Cacciapuoti C. Global epidemiology of hepatitis $\mathrm{C}$ virus infection: an up-date of the distribution and circulation of hepatitis $\mathrm{C}$ virus genotypes. World J Gastroenterol 2016;22:7824-7840.

15. Pawlotsky JM. Use and interpretation of virological tests for hepatitis C. Hepatology 2002;36(5 Suppl 1):S65-S73.

16. Moorman AC, Drobenuic J, Kamili S. Prevalence of false-positive hepatitis C antibody results, National Health and Nutrition Examination Study (NHANES) 2007-2012. J Clin Virol 2017;89:1-4.

17. Aisyah DN, Shallcross L, Hully AJ, O’Brien A, Hayward A. Assessing hepatitis $\mathrm{C}$ spontaneous clearance and understanding associated factors: a systematic review and meta-analysis. J Viral Hepat 2018;25:680-698.

18. Thomas DL, Thio CL, Martin MP, et al. Genetic variation in IL28B and spontaneous clearance of hepatitis C virus. Nature 2009;461:798-801.

19. Cho EJ, Kim SE, Suk KT, et al. Current status and strategies for hepatitis B control in Korea. Clin Mol Hepatol 2017;23:205-211.

20. Lyoo K, Song MJ, Hur W, et al. Polymorphism near the IL28B gene in Korean hepatitis $\mathrm{C}$ virus-infected patients treated with peginterferon plus ribavirin. J Clin Virol 2011;52:363-366.

21. Kim JY, Won JE, Jeong SH, et al. Acute hepatitis C in Korea: different modes of infection, high rate of spontaneous recovery, and low rate of seroconversion. J Med Virol 2011;83:1195-1202.

22. Papatheodoridis GV, Hatzakis A, Cholongitas E, et al. Hepatitis C: the beginning of the end-key elements for successful European and national strategies to eliminate HCV in Europe. J Viral Hepat 2018;25 Suppl 1:6-17.

23. Shin A, Cho ER, Kim J, et al. Factors associated with awareness of infection status among chronic hepatitis B and C carriers in Korea. Cancer Epidemiol Biomarkers Prev 2009;18:1894-1898.

24. Ahn HR, Cho SB, Chung IJ, Kweon SS. Socioeconomic differences in self- and family awareness of viral hepatitis status among carriers of hepatitis B or C in rural Korea. Am J Infect Control 2018;46:328-332.

25. Denniston MM, Klevens RM, McQuillan GM, Jiles RB. Awareness of infection, knowledge of hepatitis C, and medical followup among individuals testing positive for hepatitis C: National Health and Nutrition Examination Survey 2001-2008. Hepatology 2012;55:1652-1661.

26. Kim HS, Yang JD, El-Serag HB, Kanwal F. Awareness of chronic viral hepatitis in the United States: an update from the Na- 
Kim KA and Lee JS: Epidemiology of HCV Infection in Korea 651

tional Health and Nutrition Examination Survey. J Viral Hepat 2019;26:596-602.

27. Ki M, Choi HY, Kim KA, Jang ES, Jeong SH. Healthcare costs for chronic hepatitis C in South Korea from 2009 to 2013: an analysis of the national health insurance Claims' data. Gut Liver 2017;11:835-842. 